\title{
La tutoría en la formación inicial como self-study
}

\author{
Ana Cecilia Valencia Aguirre ${ }^{1}$ (D) @ \\ María Teresa Prieto Quezada ${ }^{1}$ (D) @ \\ José Claudio Carrillo Navarro ${ }^{1}$ (i) @ \\ ${ }^{1}$ Universidad de Guadalajara (UDG), México
}

Resumen. El propósito del presente artículo es analizar la experiencia de la formación docente inicial en el último año de la carrera de profesor de educación primaria en una escuela normal de México. Se parte del análisis de entrevistas aplicadas a un grupo de maestros en formación, la interpretación se da en el marco de los significados sociales. La formación situada de la tutoría es una estrategia formativa desde el self-study, entendida como una disciplina de investigación, que estudia de modo sistemático cómo los formadores de profesores permiten que sus estudiantes aprendan a analizar sus propias prácticas, con la intención última de tener una consciencia rigurosa de lo que hacen, para poder así producir conocimiento propio de la disciplina de la enseñanza focalizada y autoiniciada, orientada a la mejora, interactiva-colaborativa.

Desde el anterior enfoque el estudio analiza las opiniones de estudiantes normalistas o maestros en formación en el último grado de su carrera a través de un estudio de caso, con una metodología cualitativa y descriptiva. Uno de los hallazgos relevantes de este estudio muestra que la tutoría, sigue ligada a la tradición que pondera la prescripción antes que el análisis reflexivo de la práctica docente.

Palabras clave: formación inicial; self-study; tutoría; práctica docente; acompañamiento.

\section{A tutoria na formação inicial como self-study}

Resumo: O objetivo deste artigo é analisar a experiência da formação inicial de professores no último ano da carreira de professora primária em uma escola normal no México. É baseado na análise de entrevistas aplicadas a um grupo de professores em formação, a interpretação é dada no âmbito dos significados sociais. A formação situada da tutoria, é uma estratégia formativa do autoestudo, entendida como uma disciplina de pesquisa que estuda, de forma sistemática, como os formadores de professores permitem que seus alunos aprendam a analisar suas próprias práticas, com a intenção última de ter uma consciência rigorosa do que fazem, a fim de produzir conhecimento da disciplina de ensino focado e auto-iniciado, voltada para o aprimoramento, interativo-colaborativo. $A$ partir da abordagem anterior, o estudo analisa as opiniões de alunos ou professores normandos em formação no último grau de sua carreira por meio de um estudo de caso, com uma metodologia qualitativa e descritiva. Um dos achados relevantes deste estudo mostra que a tutoria ainda está vinculada à tradição que pondera a prescrição antes da análise reflexiva da prática docente.

Palavras-chave: formação inicial, self-study, tutoria, práticas de ensino, acompanhamento.

\section{Tutoring in initial education as self-study}

Abstract. The purpose of this article is to analyze the experience of initial teacher education in last year of the elementary school teacher's career in a teacher training college in Mexico. It is based on the analysis of the voices of a group of teachers in training interviewed, whose narratives are interpreted from the framework of social meanings. From the training located in the tutoring, valued as a formative strategy from the self-study, understood as a research discipline that studies, in a systematic way how teacher trainers allow their students to learn and analyze their own practices, with the ultimate intention to have a rigorous awareness of what they do, in order to improve their profession, to produce their own knowledge of the discipline of focused and self-initiated teaching, aimed at improvement, interactive-collaborative. From the previous approach, this study analyzes the opinions of students or teachers in training in the last degree of their career through a case study, with a qualitative and descriptive methodology. One of the relevant findings shows that the tutoring that takes place in the normal school referred to, is still linked to the tradition that weights the prescription before the reflexive analysis of the teaching practice.

Keywords: Initial education, self-study, tutoring, teaching practice, accompaniment. 


\section{Introducción}

\subsection{La tutoría en la formación: problemas y desafíos}

La tutoría en la formación inicial entendida como el acompañamiento situado a los normalistas ${ }^{1}$ en las escuelas de práctica, representa una acción formativa que permite integrar los saberes, el análisis y las reflexiones a la comprensión de la práctica docente; fundamentada en el modelo de la investigación-acción, su implementación implica superar desafíos en el inicio de la profesión ya que de esta experiencia dependerán algunas de las concepciones sobre el ser docente en un espacio instituido como es la escuela.

Uno de los desafíos del self-study en la formación inicial, con los que nos encontramos los formadores de futuros maestro es conocer a nuestros estudiantes y sus formas de aprendizaje, monitoreando permanentemente las mejoras de sus prácticas y acompañarlos en el desarrollo cognitivo, emocional, físico, social y moral/ético de sus procesos. También se requiere emplear estrategias que hagan transparentes los logros y toda la variedad, complejidad y fluidez de los aprendizajes. Simultáneamente, se requiere emplear métodos que evidencien los aprendizajes ante una comunidad educativa a partir de lo que se está descubriendo, resignificando y transformando la propia práctica de modo sólido, permanente y dialógico. Como señala Cornejo (2016, p. 29) “EI aprendizaje puede ser mejorado, para lo cual es esencial desafiar previamente los supuestos sustentados mediante la experiencia práctica y las múltiples perspectivas de los colegas actuales y sus reflexiones documentadas".

Esta experiencia de aprendizaje donde ligamos en una triada formativa: tutoría-situada-self-study-investigación-acción demanda evaluar el rol de los tutores en la formación inicial docente, de ahí que el propósito del presente estudio es analizar las experiencias de acompañamiento tutorial en el último grado de la carrera del profesorado, considerando que es el nivel en el que los alumnos logran cierta autonomía al estar mayor tiempo en las escuelas de práctica; lo que nos permitirá recuperar su experiencia tutorial para analizar la valoración que ellos hacen, y responder a las siguientes cuestiones: ¿Cómo viven los docentes en formación la experiencia del acompañamiento tutorial? ¿Qué experiencias han sido valoradas positivamente desde la perspectiva del self-study? ¿Cuáles han sido escasamente formativas desde el enfoque situado del self-study? Nuestra interpretación parte del análisis de la narrativa de experiencias sobre el acompañamiento tutorial durante el último semestre de la carrera, recuperadas de entrevistas semiestructuradas aplicadas a un grupo de estudiantes de una escuela normal estatal.

${ }^{1}$ A lo largo del estudio se usará el término normalistas como sinónimo de docentes en formación inicial. 
La tutoría, de acuerdo a los Planes y Programas de Estudio del año 2012 de la Licenciatura en Educación Primaria, plantea la necesidad de una formación docente centrada en la reflexión, la autonomía y el análisis de la práctica. Esta posee una dimensión formativa y, por tanto, su impacto merece ser investigado, ya que las evidencias de aprendizaje durante el acompañamiento permitirán generar elementos que contribuyan a mejorar la formación inicial de profesores.

Un elemento de interpretación son las propias experiencias que los normalistas tienen de la tutoría en cuanto a sus efectos de acompañamiento e intervención en la práctica. Según LaBoskey, citado por Cornejo (2016), el desafío para la formación docente es, proveer modalidades para que los estudiantes articulen e interroguen sus historias personales y las comprensiones resultantes. Por lo que todos los aspectos del proceso educacional constituyen un elemento vital de la enseñanza reflexiva. En el marco de la formación inicial, la tutoría privilegia el proceso de acompañamiento en las prácticas profesionales; esas prácticas profesionales son un espacio donde se concreta la formación de profesores. Fortoul (2008), investigadora mexicana, ha destacado la particularidad de la práctica al plantear su complejidad e intencionalidad como aspectos que trascienden el paradigma técnico y que se centran en una racionalidad práctica, simbólica, representacional y de legitimación en el hacer (Fortoul, 2008) donde se deben de tomar en cuenta las emociones los afectos y las costumbres de los participantes en formación inicial.

A pesar de que diversos estudios destacan la complejidad de los espacios de la práctica docente en la formación, de acuerdo a Ducoing y Fortoul (2013), sigue prevaleciendo un esquema lineal y burocrático, de desvinculación entre teoría y práctica, prescriptivo, simplista, fundado en modelos disciplinares rígidos, orientado al cumplimiento administrativo más que a la formación reflexiva; ocupado más en calificar o descalificar que en valorar experiencias para la mejora profesional.

Estos problemas se evidencian en las evaluaciones, pero también en las concepciones pedagógicas y académicas de los alumnos que egresan de las escuelas normales (Fortoul, 2008). Fortoul y otros coinciden en señalar que las prácticas en la formación inicial son territorios fundamentales y claves para reconocer problemas no resueltos desde la viabilidad de los currículos, las reformas y la estructura institucional; sin embargo su operación está imbuida en reglas que no aportan a la mejora de la calidad de los procesos formativos; por otra parte, los autores citados, critican los deficientes procesos reflexivos que los formadores desarrollan en el acompañamiento de las prácticas de sus estudiantes. Tradicionalmente la formación en las escuelas normales se caracteriza por sus estilos artesanales, paternalistas, 
dogmáticos, concentrados en el saber hacer; enfatizando más la forma que el fondo, con nociones centradas en lo inmediato, lo concreto y lo descriptivo, donde se enfatiza más en el diseño de las planificaciones de clase como instrumento infalible, que en el análisis reflexivo de las prácticas (Fortoul, 2008; Ducoing y Fortoul, 2013).

Desde las posiciones anteriores, se desprenden dos modelos explicativos, sin caer en una clasificación simplista, de la función y el papel de los docentes: a) el de la racionalidad técnica, centrada en el cumplimiento de los objetivos, la burocratización de la docencia y el papel de ejecutor de los profesores como reproductores de un currículo descriptivo en el que no participan, el modelo tecnológico; b) el de una racionalidad práctica, que se da cuando los maestros cuentan con espacios para el diálogo, el consenso y la participación en las decisiones que habrán de impactar su tarea como enseñantes (Fortoul, 2008), el modelo dialógico o de investigación acción, permanente de la realidad escolar que permite la reflexión ética, para mejorar la concreción de valores educativos con calidad, donde como señala Schön (1995, p.89) "La reflexión conduce a la experiencia in situ, es decir reflexionar mientras se está produciendo la acción, implicándose afectivamente y cognitivamente en los intercambios inciertos, cuestionando creencias y planteamientos, proponiendo y experimentando alternativas y participando en la reconstrucción".

El supuesto que guía este estudio es el de una tutoría que se sigue moviendo en ambas arenas, donde la cultura instituida constituye la gramática de la escolaridad (Tyack y Cuban, 2001), que impone una lógica prescriptiva donde cuenta más el uniforme, la formalidad, la prescripción y la normatividad que los procesos de análisis y reflexión de la práctica situada. No son dos formas maniqueas; en tal sentido, no se intenta clasificar sino comprender cómo la tutoría se sigue moviendo en dos territorios imbricados y a veces no conscientes: el de la prescripción orientado al modelo del profesor técnico, y el del análisis del profesional reflexivo fundado en un modelo de investigación acción o self-study, que combina los aspectos de la investigación tradicional en educación y el mundo de la práctica (Korthagen, 1995).

\subsection{La tutoría en la formación inicial, desde la mirada curricular}

Los Planes y Programas de Estudio (SEP, 2012) de la Licenciatura en Educación Primaria señalan que "El trabajo del formador radica, principalmente, en realizar un acompañamiento teórico-metodológico y técnico con relación a las propuestas que se elaboran, sus fundamentos, su relación con los enfoques de los planes y programas de estudios, las perspectivas de 
aprendizaje, así como las de evaluación, entre otras, y que además permitan valorar el nivel o grado de desempeño que logra el estudiante mediante sus ejecuciones" (SEP, 2012, p. 9)

Desde la anterior, los programas consideran que el acompañamiento es un proceso gradual que va del acercamiento a los espacios escolares en los primeros dos semestres, pasando por el apoyo técnico, teórico, metodológico y didáctico en los semestres de tercero a sexto; hasta llegar al séptimo y octavo semestre de la formación normalista logrando en este nivel desarrollar la autonomía y la competencia reflexiva en el estudiante.

El acompañamiento se define como un proceso formativo que requiere un proceso dialógico, comprensivo, situado en la realidad de cada práctica, alejado de la prescripción, del autoritarismo y de la imposición de un modelo de enseñanza-aprendizaje unívoco o lineal. Se reconoce desde este enfoque que la práctica es un espacio complejo, situado, contextualizado donde cada experiencia adquiere un valor predominantemente particular y donde el análisis de casos y la recuperación de la experiencia desde los diarios de clase, el análisis de evidencias y la reflexión situada privilegian el proceso de la formación inicial. Así, la tarea del tutor será: "cuestionar acerca de las razones por las cuales los estudiantes eligen un tipo de plan, una secuencia, una actividad, un material, una forma de evaluar..." (SEP, 2012, p.22).

La tarea fundamental del tutor será la de lograr la capacidad de reflexión y autocrítica sobre la práctica docente del normalista, una práctica tensionada y en una relación relativa de autonomía, ya que el practicante normalista no puede ser del todo autónomo pues el ejercicio de su docencia está subordinado, no siempre en diálogo, al de un titular del grupo de práctica. Situación que también se debe convertir en un elemento para la reflexión y el análisis de la práctica.

Durante el tiempo de práctica en las escuelas, los normalistas interactúan en dos espacios simultáneamente: las escuelas Normales y las escuelas primarias, en la primera reportan sus avances, planifican sus clases y analizan, desde marcos teóricos explicativos, las situaciones de su experiencia en el aula y en la segunda realizan la práctica docente, enfrentándose a un sinfín de problemáticas, donde están inmersos en realidades complejas que los obligan a replantear lo planificado y lo aprendido en la escuela Normal. Ambos espacios no siempre generan procesos dialógicos de formación y de integración de los saberes, la mayoría de las veces están en tensión o contradicción ya que presentan dos escenarios opuestos: las Normales con su lógica formativa, a veces tradicional, y las escuelas primarias, con sus problemáticas situadas y en contextos de burocracia vertical. 
Además de estos escenarios institucionales, se dan dos referentes en la formación, la del titular del grupo de práctica y la del formador de la escuela Normal, ambos actores formativos poseen dos ámbitos de actuación: el primero, titular del grupo, actúa de acuerdo a las tradiciones de la escuela primaria y a las prioridades que le impone un sistema escolar autoritario: evaluaciones preestablecidas, horarios, agendas impuestas por la normatividad de sus autoridades escolares y estilos de interacción contextual fundados en la tradición. Por su parte, el formador de la escuela normal está en la disyuntiva de poner en práctica un modelo basado en los planes y programas de estudio o en ajustar su modelo a las exigencias y a los tiempos programados que demandan las escuelas de práctica, generalmente terminan priorizando la segunda opción.

La función del tutor es compleja, ya que desde la perspectiva de Yurén (1999):

El tutor sostiene la función de referencia porque se constituye en el punto a partir del cual el educando puede construir un saber y enlazarse con él, es el lugar a donde se remite al estudiante y a partir del cual puede redescubrir, inventar, crear y recrear. Acompaña al estudiante en el proceso de recuperar y reconstruir su práctica, su saber, su experiencia; avanza o retrocede con él (Yurén, 1999, citada por SEP, 2012).

Es por esto que la tutoría viene a ocupar un lugar fundamental en la formación docente, ya que es un referente dialógico del self-study para dimensionar, comprender, intervenir y reflexionar la práctica. Por su parte, la práctica docente es el campo profesional donde los profesores concretan acciones, estrategias e intenciones para intervenir y transformar su espacio de enseñanza aprendizaje en un contexto instituido, la escuela primaria.

\section{El camino metodológico}

Metodológicamente se siguió una orientación cualitativa, ya que se pretendió recuperar las significaciones en torno a la experiencia de la tutoría en la práctica profesional docente de estudiantes normalistas que cursan el octavo semestre. Es un estudio exploratorio, ya que intenta acercarse y dar cuenta de la experiencia subjetiva de la formación, la cual es recuperada a través de una entrevista, que entre otros fines describe una situación determinada y se utiliza para construir nuevas categorías conceptuales (Yuni y Urbano, 2014). El trabajo tiene un énfasis cualitativo porque intenta comprender el fenómeno "desde dentro", desde un marco inductivista y subjetivo (Cook y Reichardt, 2000). 


\section{Las interrogantes que guiaron el estudio}

i) ¿Cómo fue tu experiencia de acompañamiento en la práctica profesional de octavo semestre?; ii) ¿cuáles fueron las intervenciones tutoriales que te dieron mayores elementos para mejorar tu práctica?, y iii) desde tu experiencia, ¿qué acciones no fueron formativas o no aportaron a tu práctica docente?

Siguiendo la perspectiva de Yurén (2012) se definirán como experiencias formativas aquellas que desde la narrativa de los entrevistados permitieron recuperar y reconstruir su práctica, su saber y su experiencia; elementos que los entrevistados narraron desde la vivencia personal donde expusieron lo más significativo de su práctica y las experiencias de acompañamiento que les dieron mayores aprendizajes, certezas, reflexiones, intervenciones y logros en su práctica y en el desarrollo de sus competencias docentes. Desde este marco interpretativo el análisis tendrá los siguientes tópicos: a) Una reflexión desde la práctica; b) Experiencias que aportaron elementos para intervenciones situadas; c) Elementos para la recuperación y análisis de la práctica; d) Desarrollo de autonomía y seguridad en el desempeño docente (Yurén, 1999, citada por SEP, 2012).

La investigación se realizó con 20 alumnos que cursan el último año de la carrera de Licenciatura en Educación Primaria de una escuela normal estatal pública. Al elegirse una escuela normal se aclara que es un estudio de caso, que no pretende generalizar sus resultados a otros contextos o universalizar sus conclusiones. Los criterios de elección de los alumnos son: 1) Que acepten participar en la entrevista y compartir su experiencia formativa. 2) Que estén cursando el último semestre de su licenciatura. 3) Que provengan de diversos grupos para poder comprender las diferencias en la tutoría y abarcar un abanico de posibilidades de comprensión de la misma. El análisis de la información se dio a través del análisis de contenido, apoyado en la herramienta Atlas ti que permitió la elaboración de mapas semánticos para su interpretación subsecuente.

\section{Las respuestas y los horizontes}

Las respuestas de los entrevistados no son solo puntos de vista sin más, sino significaciones comprendidas como relatos cargados de sentidos en torno a experiencias, situaciones contextos y vivencias; las narraciones no se reducen ni a conceptos, ni a unidades lingüísticas sino a redes de significación. Estas narrativas construyen subjetivaciones desde mundos cargados de significaciones en interacción relacionadas con una cotidianidad donde se articulan y a la vez se tensionan continuamente. De ahí que el mundo social es simbólico y dinámico (Zizek, 1992), punto de encuentro 
donde se configuran y articulan las significaciones cotidianas, espacio de la resignificación de los sistemas de significado donde también: se develan las aspiraciones y las esperanzas (Treviño y Cruz, 2013, p. 53).

Vistas desde la anterior perspectiva, las respuestas de los normalistas nos abren horizontes donde se enlazan sentidos de mundo y expectativas. Las respuestas no son solo doxas aisladas, sino significados cargados de mundo, desde ahí se analizan las respuestas a las interrogantes.

A la pregunta: ¿Cuál fue tu experiencia de acompañamiento en la práctica profesional enfatizando en aquellas intervenciones tutoriales que te dieron mayores elementos para mejorar tu práctica? los normalistas señalaron que la mayor riqueza fue la recuperación y el análisis de la práctica. Del total se eligen las siguientes descripciones

[...] con el tutor nos grabamos, luego veíamos nuestro video y nosotros también veíamos lo que estábamos mal pues, o lo que estábamos bien (N1).

[...] luego nos dijo el tutor, que una cosa es lo que nosotros vemos, pero también lo tuvimos que pasar a otro compañero y ahí ya estaban viendo otras cosas, que nosotros, ante nosotros somos ciegos también un poquito... (N2).

[...] se hizo una reflexión; a nosotros siempre se nos pidió una bitácora de alumnos, diario de campo y diario de profesor entonces era analizar todo lo que hiciste, cómo lo veías tú y en realidad cómo fue sucediendo ya viéndolo estando fuera del campo en el aula ya te dabas cuenta de muchas cosas... (N3).

[...] sus observaciones -del tutor- siempre fueron muy concretas, muy útiles, pero si me hubiera gustado que en los diferentes semestres que fueran más constantes las observaciones para no solo sentir yo que hubo mejorías en mis momentos de práctica, sino que también me dijeran "has mejorado en esto, pero te sigue fallando esto... (N4).

Otra de las acciones tutoriales valoradas por los normalistas fueron aquellas que ofrecieron un apoyo para intervenir pedagógicamente y de manera idónea situaciones nunca antes enfrentadas, como lo fue el caso de aprendizajes no esperados:

[...] me tocó trabajar con una niña llamada $X$ que tenía problemas para escuchar, entonces yo me acerqué con la maestra (la tutora) porque eso era nuevo para mí, eran cuarenta y cinco niñas en el grupo y estaba incluida entre ellas $X$, entonces yo me sentía como que atrapada, yo decía "auxilio" porque no sabía qué hacer, no sabía y me sentía atada de manos y la maestra titular me decía "no es que a mí déjame a X", pero yo quería, yo quería experimentar lo que era trabajar con ella, entonces la tutora me brindó tanto teoría como experiencia de cómo acercarme a la pequeña, cómo diseñar actividades que no se vieran tan separadas del grupo (N5). 
Las acciones tutoriales mejor valoradas fueron la retroalimentación y el estar al pendiente del proceso, dar seguimiento sobre la marcha, las recomendaciones de apoyo al proceso. La retroalimentación es entendida como aquella acción donde el alumno recibe observaciones y sugerencias concretas para mejorar tanto su práctica docente como sus intervenciones en el aula. Siendo así, los alumnos valoraron la asistencia del tutor al espacio de la práctica, señalaron la importancia de ser observados y recibir comentarios de parte del tutor, como podemos ver estas narrativas:

[...] darnos retroalimentación y todas esas cosas, siento que a mí me gustó mucho esa parte y me ayudó mucho (N6).

Yo pienso que el tutor es propositivo porque siempre está al pendiente de lo que estás haciendo y sugiere cosas para que cambies o para que mejores, siempre es en pro de tu práctica (N7).

[...] sus observaciones siempre fueron muy concretas, muy útiles, pero si me hubiera gustado que en los diferentes semestres que he pasado no que estuvieran todos los días conmigo, pero sí que fueran más constantes las observaciones para no solo sentir yo que hubo mejorías en mis momentos de práctica, sino que también me dijeran "has mejorado en esto, pero te sigue fallando esto (N8).

[...] el hecho de que la maestra fuera a la escuela primaria a observar nuestras clases, después a darnos retroalimentación y todas esas cosas siento que a mí me gustó mucho esa parte y me ayudó mucho (N10).

En séptimo la tutora, excelente maestra, la verdad a pesar de que ella nunca fue a la primaria, siempre estaba al pendiente de cómo iba nuestro proceso, de nuestras debilidades, de lo que nos hacía falta, era muy flexible y siempre todo era como para fortalecer nuestra práctica, para favorecer nuestros aprendizajes (N11).

En octavo el tutor, él sí estuvo al pendiente de ir a las escuelas, de hecho, algo que me gustó mucho el que grabó, entrevistó a nuestro maestro titular del grupo...y después nos entregó la grabación a nosotros (N12).

Grabamos una clase y después el compañero observaba la clase y nos hacía observaciones de lo que nos hacía falta, mediante una rúbrica, no recuerdo. Pero sí venía como lo que debíamos haber hecho y qué es 10 que el compañero observaba (N20).

La retroalimentación en séptimo era más en clase, "a ver y ahora cómo les fue, qué les pasó" y luego la docente -ella- nos decía y nos daba estrategias, siempre nos daba su punto de vista (N18).

El tercer elemento ponderado en la tutoría fue el proceso que les permitió ejercitar la reflexión sobre la práctica, a ese respecto los normalistas señalaron que:

En octavo, fue más estar reflexionando sobre mi práctica: "esto hice bien, esto hice mal". Ah, porque también esta hoja de observación la llenaba cada quince días el maestro titular, la misma que nos hizo el tutor la hacía 
el maestro titular cada quince días, entonces era como ver "ah me está fallando el control de grupo, entonces ahora investigo qué me sirve para el control del grupo". Y era como estar reflexionando sobre mi práctica (N12).

$Y$ en séptimo fue pues esto de aprender a planificar y también, ahorita que lo menciono, también reflexionamos sobre la práctica, pero ayudados con el diario de clase, la maestra nos enseñó cómo hacer la reflexión (N20).

En octavo, yo siento que me sirvieron más todas las observaciones hechas por el tutor, el docente de grupo, los compañeros de clase y yo misma las observaciones que yo hacía de las clases me sirvieron para reflexionar. Fue más útil la retroalimentación de las observaciones (N18).

De acuerdo a las narrativas, se evidencia un uso sistemático de instrumentos como lo son: la videograbación, el diario de clases, el diario rotativo, los registros de clase, los guiones de observación. Los normalistas nunca refieren autores o teorías, sin embargo, hablan de técnicas para el análisis desde un ámbito artesanal de ejecución. Así podemos destacar acciones llevadas a cabo a partir de la tutoría como: i) uso de instrumentos de registro, ii) recuperación de la práctica, iii) análisis, iv) reflexión, desde la confrontación entre el hacer y lo que los otros observan, como podemos apreciar en el siguiente fragmento:

[...] nos pidió una bitácora de alumnos, diario de campo y diario de profesor entonces era analizar todo lo que hiciste, cómo lo veías tú y en realidad cómo fue sucediendo ya viéndolo estando fuera del campo en el aula ya te dabas cuenta de muchas cosas (N22).

\section{Tipo de acciones tutoriales no formativas}

En este rubro, podemos distinguir desde la narrativa de los normalistas por oposición a las acciones favorables, aquellas que no les permitieron: reflexionar, lograr autonomía, mejorar e intervenir su práctica, mismas que se enuncian a continuación:

En séptimo cuando el maestro tutor fue, le digo que estaba de pie observando y él llenó una como una hoja de observación, y ahí tenía varios aspectos que nosotros deberíamos de cumplir y era como una escala de si lo hicimos sobresaliente, suficiente, deficiente y ya él palomeaba lo que hicimos... Eso me pareció desfavorable, porque su instrumento era para calificar aspectos que no tenían nada que ver con la práctica (N15).

Los estudiantes señalan que este tipo de acciones donde los tutores Ilevan una hoja de evaluación con aspectos que debe cumplir un practicante no son pertinentes, ya que como ellos señalan: 
A veces, va a una hora o en un día donde los alumnos están muy inquietos y nos evalúan mal porque dicen que no tenemos control grupal - ¿cómo vamos a tenerlo? - si los niños ya están enfadados por una situación ajena a nuestra planeación (N14).

No me gusta que vayan con el afán de decirnos que estamos mal en todo, porque no tenemos la planificación en el escritorio, o porque ese día llevamos pants y tenis porque nos tocó educación física -yo me preguntó ¿acaso son los tenis o el pants lo indispensable para un ambiente de aprendizaje? ¡no! Hay otros aspectos que nunca ven porque no está en su rúbrica (N20).

El tutor a veces no inspira confianza, porque lejos de apoyar va a calificar sin ver la realidad de nuestras escuelas, revisan lo que ellos quieren ver, no lo que realmente deben ver de acuerdo a nuestras condiciones- a veces- no me escuchan, solo lo que ellos dicen que es bueno (N16).

\subsection{La expectativa de una buena tutoría}

Una de las situaciones ponderadas por los normalistas fue la recuperación de su práctica, la valoración de parte de su tutor; la retroalimentación, el apoyo; el entender que la mejora es un proceso gradual; demandan el derecho de reconocer sus errores, pero el compromiso de mejorar sin que esto los determine con una baja calificación de parte del tutor:

[...] que el tutor se dé cuenta que estoy practicando, que estoy tratando de mejorar, entonces valóreme que a lo mejor lo hice mal, pero voy a mejorarlo y no el "ah, lo hiciste mal y estás mal y tienes una baja calificación (N10).

[...] que me den la oportunidad de equivocarme (N12).

Desde las anteriores consideraciones, la tutoría debe considerar el error como una oportunidad para el aprendizaje y la mejora; no como un elemento para calificar o determinar los saberes. De la Torre acuña el concepto de pedagogía del error para situar este fenómeno desde una mirada innovadora:

La pedagogía del error, por su parte, valorará lo que ya se tiene conseguido y analizará, a través del error, lo que falta mejorar. Desde una perspectiva constructiva, el error es un desajuste entre lo esperado y lo obtenido (De la Torre, 2004, p.86).

Desde esta mirada, un acompañamiento no puede estar centrado en un logro de objetivos previstos, sino en una perspectiva abierta y situada donde los sujetos en formación están en escenarios inciertos, que no garantizan la eficacia de la prescripción, sino que obligan a comprender la docencia desde una dimensión compleja. Al respecto, señala De la Torre (2004, p.87) "En tal sentido, se fijan objetivos, pero de forma abierta y flexible, de tal modo que puedan modificarse en base al análisis que se va realizando durante el proceso de aprendizaje". Este paradigma, implica flexibilidad en 
el modelo tutorial como bien lo han planteado las narrativas de los alumnos de la escuela Normal, por otra parte, es significativo el ocuparse menos en una calificación que un proceso formativo.

La comunicación es otro factor que los normalistas consideran relevante; la comunicación debe ser asertiva y abrir horizontes para la intervención y la mejora, se debe dar en un ambiente de confianza y reconocimiento de las condiciones propias de la práctica donde puede haber factores de incertidumbre para los normalistas, pero con el acompañamiento como fortaleza, lo cual les permite asumir los retos de la práctica docente:

[...] yo siento que, que fue un proceso más acompañado, a lo mejor se va a oír mal, pero más maternalista, yo me sentía como protegida, sentía que alguien iba de mi mano, pero me sirvió, porque me proporcionó esta experiencia de trabajar con algo con lo que no había trabajado (N10).

En esta narrativa vemos que la comunicación entre la alumna y la tutora se acompaña de comprensión, en el sentido de estar situada en el escenario de los problemas, el acompañamiento es dialógico, no se impone, se sitúa a partir de las condiciones y escenarios donde se demanda una intervención acorde a dicha situación. Otro factor es la flexibilidad, que implica la capacidad de que el tutor comprenda y apoye al normalista haciendo a un lado un esquema prescriptivo elaborado desde un escritorio; esquema que la mayoría de las veces no pondera las condiciones de la práctica, ni el escenario incierto que enfrentan los docentes en las aulas; tampoco incluye las características y estilos de la docencia del sujeto en formación. Mercado (2013) nos advierte de los riesgos de la prescripción en los procesos de acompañamiento tutorial:

Desde la escuela Normal planificamos, organizamos y prevemos una práctica que, cuando la confrontamos con la "realidad de la escuela" nos devela los límites de la prescripción y nos alerta acerca de la incertidumbre y la complejidad de los espacios escolares donde nos insertamos (Mercado, 2013, p. 89).

Esta perspectiva tiene que ver con una concepción dinámica de la práctica docente, que se instala en un paradigma de complejidad, abierta, cambiante y flexible de acuerdo a las condiciones de los contextos donde se desarrolla. La concepción de aprendizaje también está en juego, la visión de centrar el aprendizaje en una mera escolarización formal no integra la experiencia situada como clave fundamental de la concreción de diversos tipos de aprendizaje, que siguiendo la tesis de Delval (2001) se dan en la práctica, en la vida social, en el significado de la vida y en teorías científicas. Por su parte, Mercado (2013) señala que las escuelas de práctica son un elemento fundamental para repensar la formación e innovar el proceso de acompaña- 
miento, de la visita guiada por esquemas prescriptivos a un acompañamiento situado, donde los discursos y las prácticas de los normalistas y los tutores entran en conflicto y crisis al tener que superar dicho carácter prescriptivo.

\section{Discusión}

De acuerdo a lo anterior, existen dos modelos de visita tutorial, la que se centra en una observación situada donde se privilegian los instrumentos de observación abiertos y la visita guiada con instrumentos cerrados donde se privilegian las rúbricas o las listas de cotejo, con aspectos formales y técnicos como son: la vestimenta del normalista, la puntualidad, la entrega de planificaciones en tiempo y forma, el uso de material, y otros. Si bien estas listas de cotejo son importantes, lo es más la manera como los normalistas interactúan con los alumnos de las escuelas, logran desarrollar ambientes de aprendizaje y generan condiciones propicias para el logro de aprendizajes situados. En este sentido, algunas de las visitas de los tutores se centran en aspectos formales y prescriptivos dejando de lado las experiencias formativas de la práctica.

De acuerdo a las voces de los entrevistados la mayoría de las intervenciones del tutor exigen su presencia, ir a la escuela y atender el conflicto. Conflictos, la mayoría de las veces de interacción entre los miembros de la comunidad escolar, donde se ven implicados los normalistas ante situaciones que van del acoso escolar, de maltrato hacia algún miembro; de problemas de comunicación; de tolerancia y de respeto entre los implicados; hasta problemas de seguridad emocional en los normalistas; de depresión; de crisis emocional. En este escenario ¿Cuál es el acompañamiento pertinente? Un normalista tiene la palabra:

[...] aquel que apoya mi proceso, que me brinda compañía, empatía, afecto, comprensión. A veces necesito una palabra que me brinde seguridad, que recupere mi dignidad, cuando la titular me quiere ver menos, me compara con lo que ella antes hacía, me dice que ya no hay buenos practicantes, que ya no hacemos material, ni frisos como en sus tiempos, donde era muy matado ser practicante... (N19).

La empatía y afecto, son factores fundamentales para guiar el acompañamiento tutorial, porque se denuncian escenarios de violencia hacia el trabajo de los normalistas por parte de los propios miembros de la comunidad escolar. La actitud colaborativa, el que el tutor ofrezca apoyo y se involucre de manera asertiva en las problemáticas que el practicante enfrenta, 
otorgue confianza y cercanía, son aspectos que permiten la construcción de una práctica docente en un contexto de reconocimiento, de acompañamiento hospitalario y de responsabilidad (Bárcena y Mèlich, 2014).

En otros términos, la relación del docente o tutor hacia el alumno o discente tiene que fundarse en la responsabilidad ética, en un vínculo dialógico y de acompañamiento, es decir, en la ética. Mèlich, citado por Ortega (2016, p. 247), al respecto señala que "la ética es la forma en que los seres humanos en cada momento de nuestra vida, nos situamos ante el mundo y ante el otro, la forma de responder de él y ante él; "la forma que cada ser humano tiene de encarar al otro en un espacio íntimo de responder, singular e ineludiblemente, de é y ante él" (Mèlich, 2010, p.96).

Fuentealba e Imbarack (2014) proponen re-pensar la política educativa visibilizando el compromiso docente como soporte dentro de la formación de los futuros maestros y lugar de encuentro para marcar diferencias en contextos de desempeño docente. "De ahí la relevancia de pensar las reformas educativas a partir de lo que significa que la responsabilidad de levantar el estándar de calidad, diseñar políticas e implementarlas no puede eludir lo que implica ser docente ni la participación de estos en el diseño de procesos de reforma" Fuentealba e Imbarack (2014). Un docente da cuenta de su compromiso desde el primer momento en que marca la diferencia en el aprendizaje y procesos de sus alumnos donde ellos muestras lo que saben y como enseñan su conocimiento pedagógico, disciplinar, profesional, así como también sus creencias, actitudes y valores, tendrán un impacto significativo en sus alumnos e instituciones en la cual se desempeñen.

\section{Conclusiones y reflexiones finales}

Las conclusiones nos conducen a comprender que la lógica del acompañamiento se ve permeada por acciones que han permitido a los normalistas sentirse acompañados, reflexionar sobre su hacer docente y dan cuenta del uso constructivo y reflexivo de instrumentos y técnicas para la recuperación de la práctica como el diario de clase, la videograbación, el audio grabación, la entrevista, el registro y el guion de observación. Sin embargo, aún prevalecen acciones prescriptivas, basadas en rúbricas o listas de cotejo que no se articulan a escenarios particulares de la práctica situada.

No fue la intención de este estudio concluir en tipos de tutoría, sino más bien analizar desde las narrativas aquellas acciones que favorecen el proceso del análisis y reflexión de la práctica, que generan autonomía y seguridad profesional, así como procesos de retroalimentación para la me- 
jora continua de la enseñanza y el aprendizaje; y aquellas que no fomentan estos procesos. Así, las acciones formativas que destacaron las narrativas fueron el apoyo, la observación, la retroalimentación, las orientaciones y las recomendaciones en el proceso, se valoró el papel de la retroalimentación, como elemento clave para la mejora de la práctica y la generación de la reflexividad sobre el quehacer docente.

Es necesario señalar que la mayor parte de las narrativas de los normalistas consideraron que la tutoría se orientó en el último semestre de la carrera a la reflexión sobre la práctica, sin embargo, no hicieron alusión a referentes teórico-conceptuales que fundamentaran dicha actividad. Esto es significativo ya que las prácticas de los normalistas siguen siendo guiadas por intuiciones y experiencias basadas en soluciones concretas e inmediatas ante problemas prácticos, sin argumentos o referentes fundados en saberes del dominio científico-pedagógico.

Las voces demandaron una tutoría centrada en el apoyo ante el manejo de emociones, afectos y empatías dado los contextos de conflicto, violencia y crisis que los docentes en formación dijeron vivir en sus escuelas de práctica; la necesidad de un acompañamiento hospitalario en escenarios de incertidumbre escolar, ese fue el deseo y a la vez la expectativa, en tal sentido: "Colocarse en la perspectiva de la segunda persona exige el adelanto de una forma de reconocimiento que no pude aprehenderse completamente en conceptos cognitivos o epistémicos, porque contiene siempre un elemento de apertura, entrega o amor involuntarios" (Mèlich, 2006, p. 31), en ese sentido la relación con el otro es también un elemento de relación de presencia-ausencia incondicionada, por ello el mismo autor señala que "Educar es dar sin esperar nada a cambio. En este "dar" el maestro no solamente "da", sino también "se da". El "dar" educativo es un "darse". En la relación educativa no solamente se da algo sino también se da alguien" (Mèlich, 2006, p. 33). Las particularidades del compromiso se evidencian en "profesores que creen firmemente que pueden marcar una diferencia en el aprendizaje y resultados de sus estudiantes por lo que ellos son, lo que ellos saben y cómo ellos enseñan" (Day, 2007, p. 254); asimismo los profesores comprometidos tienen la certeza de que tanto ellos -su identidad- como su trabajo -conocimiento pedagógico, disciplinar, profesional-; las estrategias de enseñanza que utilizan, así como también sus creencias, actitudes y valores, tendrán un impacto significativo en sus alumnos e instituciones en las cuales trabajan. Es decir, colocarse en el otro, la Compatía (Paz, 2003, p. 649) que consiste en el sentimiento de participar en las emociones del otro, abrazarlo, situarse en él, comprender su condición para entenderlo, acercarse, empatizar con su entorno con propósitos comprensivos. 
La premisa del acompañamiento educativo es el reconocimiento de los rostros: las miradas, sus expresiones, sus sentidos y significados como plataforma para la generación de emociones y desarrollos intelectuales con sentido y significado para quienes quieren aprender. Los "otros" de carne y hueso, no sólo son una entidad óntica, con la que me encuentro o me tropiezo, son seres con una historia de vida, plagada de emociones, contradicciones, gustos y preferencias existenciales, sexuales ideológicas, con aspiraciones de vida bien desarrolladas o mutiladas por los entornos en los que viven, son seres con sentido impuesto por las construcciones sociales externas 0 producto de las imbricaciones de sus "Yo (es) con el mundo.

La relación educativa, que se da en la formación situada desde el acompañamiento, implica vínculo, relación, interacción, no hay una relación receptor- receptáculo, el proceso implica reciprocidad y alimento mutuo, la dialéctica de los entornos nos modifica y nos trastoca nuestros modos de ver, sentir e interactuar en las cosas, Tocamos y somos tocados por el contexto, lo influimos y somos producto de sus circunstancias. Por ello no hay caminos rígidos, ni formas únicas de pensar el mundo de los jóvenes formadores en situaciones educativas, cada ecología requiere una epistemología para su comprensión. La idea de marcos normativo-comprensivos absolutos es un obstáculo para acercarse a lo real, nos aleja del mundo, nos impide intervenir con inteligencia creadora, nos bloquea porvenir, de universos pedagógicos horizontales. Levinas citado por Mèlich (2006). señala que la relación ética con los otros es una relación cara a cara, rostro a rostro. Por ello dicen Bárcena y Mèlich (2014) "No hay manera de saber qué respuesta es la correcta antes de que se haya producido la interpelación. Es por esta razón que la respuesta ética es radicalmente aposteriorística. Por eso, la forma que debería tener la respuesta ética no podría establecerse de antemano. No es posible decidir a priori, desde una perspectiva ética, cómo hay que responder". Y ese es el sentido de un acompañamiento situado y formativo que favorece el self-study sin olvidar la posición de reconocimiento ético del formador en proceso.

\section{Referencias bibliográficas}

Bárcena, F. y Mèlich, J-C. (2014). La educación como acontecimiento ético. $2^{a}$ edición. Buenos Aires: Miño y Dávila. Disponible en https://bit.ly/35zBoUl

Cook, T. D. y Reichardt, CH. (2000). Métodos cuantitativos y cualitativos en investigación evaluativa. Madrid: Morata.

Cornejo, J. (2016). El Self-Study de la práctica de los formadores de futuros profesores: bases teóricas, características y modalidades metodológicas. En T. Russell, R. Fuentealba y C. Hirmas (Comp.) . Formadores de formadores, descubriendo la propia voz a través del self-study. Santiago de Chile: OEI. Disponible en https://bit.ly/2UmR8c9uu 
Day, C. (2006). Pasión por enseñar: la identidad personal y profesional del docente y sus valores (Vol. 4). Narcea ediciones.

De la Torre, S. (2004). Aprender de los errores. El tratamiento didáctico de los errores como estrategias innovadoras. Argentina: Editorial Magisterio del Río dela Plata.

Delval, J. (2001). Aprender en la vida y en la escuela. Madrid: Editorial Morata

Ducoing, P. y Fortoul B. (Coord.) (2013). Procesos de formación 2002-2011. Volumen I. Estados del conocimiento 2002-2012. México: Consejo Mexicano de Investigación Educativa.

Fortoul, M. B. (2008). La concepción de la enseñanza según los estudiantes del último año de la licenciatura en Educación primaria en México. Perfiles educativos, 30(119), 72-89.

Fuentealba, R. \& Imbarack, P. (2014). Compromiso docente, una interpelación al sentido de la profesionalidad en tiempos de cambio. Estudios pedagógicos (Valdivia), 40(especial), 257-273.

Korthagen, F.A.J. (1995). A reflection on five reflective accounts. Theme issue self-study and living educational theory. Teacher Educational Quarterly, 22(3), pp. 99-105

Mèlich, J-C. (2006). Tres ensayos de Filosofía de la Educación. Buenos Aires: Miño y Dávila.

Mèlich, J-C. (2010). Ética de la compasión. Barcelona: Herder.

Mercado, E. (2013). Acompañar al otro: saberes y prácticas de los formadores de docentes. México: Díaz de Santos.

Ortega, P. (2016). La ética de la compasión en la pedagogía de la alteridad. Revista española de pedagogía, LXXIV(264), 243-264.

Paz, O. (2003). Ideas y Costumbres. (La letra y el cetro. Usos y símbolos). Obras Completas VI, Barcelona, p.649

SEP (2012). Plan de Estudios para la Formación de Maestros de Educación Primaria. México: Secretaría de Educación Pública.

Schön, D. (1995). Como piensan los profesionales en la acción: el práctico reflexivo, en formación de formadores, materiales para la formación de educadores desde la educación superior. N 1, CEAAL, Chile; Dimensión educativa, Bogotá.

Treviño, E. y Cruz, R. (2014). La Reforma Integral de la Educación Básica en el discurso docente. Perfiles Educativos, XXXVI(144), 50-68

Tyack, D. y Cuban, L. (2001): En busca de la utopía. Un siglo de reformas de las escuelas públicas, Ciudad de México, FCE.

Yuni, J.A. y Urbano, C. A. (2014). Técnicas para investigar: recursos metodológicos para la preparación de proyectos de investigación. Córdoba: Brujas.

Yurén, T. (1999). Formación, horizonte del quehacer académico. México: UPN

Yurén, T. (2012). Formación, eticidad y relación pedagógica. En Formación y puesta a distancia. Su dimensión ética (pp.27-41). México: Paidós.

Zizek, S. (1992), El sublime objeto de la ideología, México: Siglo XXI. 